\title{
In vitro bioassessment of the immunomodulatory activity of Saccharomyces cerevisiae components using bovine macrophages and Mycobacterium avium ssp. paratuberculosis
}

\author{
Z. Li, ${ }^{*}$ H. Kang, ${ }^{*}$ Q. You, ${ }^{*}$ F. Ossa,† P. Mead, ${ }^{*}$ M. Quinton, ${ }^{*}$ and N. A. Karrow \\ *Department of Animal Biosciences, University of Guelph, Guelph, ON, Canada, N1G 2W1 \\ †Lallemand Inc., Montréal, QC, Canada, H4P 2R2
}

\section{ABSTRACT}

The yeast Saccharomyces cerevisiae and its components are used for the prevention and treatment of enteric disease in different species; therefore, they may also be useful for preventing Johne's disease, a chronic inflammatory bowel disease of ruminants caused by Mycobacterium avium ssp. paratuberculosis (MAP). The objective of this study was to identify potential immunomodulatory $S$. cerevisiae components using a bovine macrophage cell line (BOMAC). The BOMAC phagocytic activity, reactive oxygen species production, and immune-related gene (IL6, IL10, IL12p40, IL13, IL23), transforming growth factor $\beta, A R G 1, C A S P 1$, and inducible nitric oxide synthase expression were investigated when BOMAC were cocultured with cell wall components from 4 different strains (A, B, C, and D) and 2 forms of dead yeast from strain A. The BOMAC phagocytosis of mCherry-labeled MAP was concentration-dependently attenuated when BOMAC were cocultured with yeast components for $6 \mathrm{~h}$. Each yeast derivative also induced a concentration-dependent increase in BOMAC reactive oxygen species production after a 6-h exposure. In addition, BOMAC mRNA expression of the immune-related genes was investigated after 6 and $24 \mathrm{~h}$ of exposure to yeast components. All yeast components were found to regulate the immunomodulatory genes of BOMAC; however, the response varied among components and over time. The in vitro bioassessment studies reported here suggest that dead yeast and its cell wall components may be useful for modulating macrophage function before or during MAP infection.

Key words: Saccharomyces cerevisiae, Mycobacterium avium ssp. paratuberculosis, macrophage function

Received September 8, 2017.

Accepted February 24, 2018.

${ }^{1}$ Corresponding author: nkarrow@uoguelph.ca
INTRODUCTION

Dairy producers have been using commercially available yeast probiotics and their components as feed supplements for almost 2 decades based on findings that these products improve animal production, promote health, and reduce the need for antibiotic use (Jouany et al., 1998; Salama et al., 2002; Ganan et al., 2009). For instance, studies have demonstrated that supplementing the ruminant diet with specific strains of Saccharomyces cerevisiae improves feed intake (Williams et al., 1991; Robinson and Garrett, 1999), weight gain (Salama et al., 2002), and fiber digestion (Wohlt et al., 1998; Kamel et al., 2004). It has been reported that live yeast stabilizes pH (Doreau and Jouany, 1998; Jouany et al., 1998) and the number of anaerobic cellulolytic bacteria in the rumen (Mosoni et al., 2007; Silberberg et al., 2013). Studies have also shown that $S$. cerevisiae cell wall components (CWC) adhere to various enteric pathogens, thereby reducing their ability to invade host cells (Ganan et al., 2009). More specifically, we have shown that CWC from specific $S$. cerevisiae strains can reduce attachment of Mycobacterium avium ssp. paratuberculosis (MAP) to different types of epithelial cells (Li et al., 2016). Mycobacterium avium ssp. paratuberculosis is an intracellular pathogen that invades intestinal epithelial cells (M-cells) and is subsequently transferred to underlying macrophages; because MAP is capable of evading macrophage-killing mechanisms, this innate immune cell is an important target cell for MAP survival and replication (Kuehnel et al., 2001). Mycobacterium avium ssp. paratuberculosis is the causative agent of Johne's disease, an inflammatory bowel disease of ruminants. Neonatal calves and calves less than 6 mo of age are highly susceptible to MAP infection (Hines et al., 1995; Veterinary Laboratories Agency, 2008), in part because their acquired immune system is underdeveloped during this exposure period (Whitlock and Buergelt, 1996).

In addition to having nutritional and antimicrobial properties, there is evidence that $S$. cerevisiae and its 
CWC have immunomodulatory properties that can affect both the innate and acquired immune systems (Ganner and Schatzmayr, 2012). Cell wall components can be used as an adjuvant to enhance vaccine efficacy, increase passive immunity (Short et al., 2016), and stimulate trained immunity and may stimulate the immune system following sepsis, which - if one survives - can result in long-term immunosuppression (Novakovic et al., 2016). Beta-glucans, for example, which are the major components of the yeast cell wall, have been shown to stimulate immune function, including upregulating macrophage proinflammatory cytokine and chemokine expression and inducing production of reactive oxygen species (ROS; Olson et al., 1996; Williams, 1997). For instance, $\beta$-glucan and $\beta$-glucan-rich zymosan have been found to increase the production of tumor necrosis factor- $\alpha$ by rodent macrophages (Olson et al., 1996). In addition, $\beta$-glucans promote leukocyte activity, which increases host survival against pathogenic infections. Rodríguez et al. (2009), for example, showed that an injection of $\beta$-glucan before Aeromonas hydrophila challenge significantly enhanced survival of zebrafish.

In addition to $\beta$-glucan, yeast cell wall mannan-oligosaccharides (MOS) are able to modulate the immune system (Staykov et al., 2007; Torrecillas et al., 2007; Castro-Osses et al., 2017). For example, higher IL-8 expression was reported in rainbow trout that were supplemented with MOS and challenged with Vibrio anguillarum (Castro-Osses et al., 2017); IL-8 controls the trafficking of immune cells, especially neutrophils (Mukaida et al., 1998). Mannan-oligosaccharides have also been found to significantly increase lysozyme concentration and improve complement activation, both of which mediate host defense against pathogens. Similarly, the immunomodulatory effect of MOS has also been reported in mammals (Newman and Newman, 2001; White et al., 2002). In one study, White et al. (2002) reported that pigs fed MOS tended $(P<0.10)$ to have higher serum IgG levels than controls; in other words, certain humoral immune proteins appear to be enhanced by feeding MOS.

Given these potential immunomodulatory properties of $S$. cerevisiae and its CWC, we hypothesized that CWC from 4 strains of $S$. cerevisiae (A, B, C, and D) and 2 different forms of dead strain A yeast (inactive and autolyzed yeast) would differentially affect macrophage function. To test this hypothesis, bovine macrophage (BOMAC) viability, phagocytosis of MAP, production of ROS, and expression of immune-related genes were assessed at various concentrations of CWC from yeast strains A, B, C, and D and inactive and autolyzed yeast strain A.

\section{MATERIALS AND METHODS}

\section{Preparation of MAP Infection Stock}

The mCherry-labeled MAP that was used in the present study was developed by Mead (2013) using the clinical isolate Gc86 strain previously isolated in the laboratory of Lucy Mutharia by Melinda Raymond (Department of Molecular and Cellular Biology, University of Guelph, Guelph, ON, Canada). The plasmid (pMADDOGPM5) containing mCherry was electroporated into the Gc86 strain to construct the mCherryMAP based on the method described by Dower et al. (1988), and the fluorescent mCherry-MAP was visualized by microscope using a $590-\mathrm{nm}$ excitation filter. The MAP stock was prepared according to the procedure previously described by Li et al. (2016); quantification of mCherry-MAP was based on measurement of fluorescence (excitation $587 \mathrm{~nm}$, emission $610 \mathrm{~nm}$ ).

\section{BOMAC Cell Line and Culture Conditions}

The BOMAC cell line (Stabel and Stabel, 1995), derived from peritoneal macrophages that were transfected with SV40 plasmid DNA, was used in this study to characterize $S$. cerevisiae bioactivity in vitro. The transformed cell line retained the morphology of resident peritoneal macrophages, such as nonspecific esterase activity and positive lysozyme activity. The BOMAC were cultured in T75 tissue culture flasks (Corning, Tewksbury, MA) at $37^{\circ} \mathrm{C}$ with $5 \% \mathrm{CO}_{2}$ in RPMI-1640 medium (Invitrogen, Burlington, ON, Canada) supplemented with $2.0 \mathrm{~m} M$ L-glutamine, $10 \%$ heat-inactivated fetal bovine serum (FBS; Invitrogen), $2.5 \mathrm{~m} M$ HEPES buffer (Invitrogen), $1 \mathrm{~m} M$ sodium pyruvate (Invitrogen), and 1\% antibiotic-antimycotic [100 $\mathrm{U} / \mathrm{mL}$ of penicillin, $100 \mu \mathrm{g} / \mathrm{mL}$ of streptomycin, and $0.25 \mu \mathrm{g} / \mathrm{mL}$ of amphotericin B (Fungizone); Invitrogen]

\section{Assessment of BOMAC Viability Following Exposure to $S$. cerevisiae CWC}

Because $S$. cerevisiae CWC were previously found to reduce bovine epithelial cell viability at higher concentrations (Li et al., 2016), it was necessary to assess BOMAC viability following exposure to ensure that bioactivity of $S$. cerevisiae CWC was assessed at sublethal concentrations. After reaching 80 to $100 \%$ confluence, BOMAC were washed with warm PBS (Sigma-Aldrich, St. Louis, MO), dislodged with TrypLE Express (Invitrogen) for $5 \mathrm{~min}$, and counted with $0.4 \%$ trypan blue using a hemocytometer chamber slide.

Cells were seeded into black 96-well flat-bottomed plates (Corning; $5 \times 10^{4}$ cells/well) in cell medium 
that did not contain amphotericin $\mathrm{B}$ or other antibiotics and incubated at $37^{\circ} \mathrm{C}$ with $5 \% \mathrm{CO}_{2}$ overnight $(17 \mathrm{~h})$. Because $S$. cerevisiae $\mathrm{CWC}$ were previously found to reduce bovine epithelial cell viability at higher concentrations ( $\mathrm{Li}$ et al., 2016), it was necessary to assess BOMAC viability following exposure to a similar range of concentrations to ensure that bioactivity of $S$. cerevisiae components was assessed at sublethal concentrations; these concentrations are compatible with concentrations used in vivo (Middelbos et al., 2007). Cells were then exposed for $6 \mathrm{~h}$ to a range of concentrations $(0.25,0.5,1,2,6,8$, and $16 \mathrm{mg} / \mathrm{mL})$ of $S$. cerevisiae CWC from stains A, B, C, and D and 2 forms of dead S. cerevisiae strain A (provided by Lallemand Inc., Montreal, QC, Canada) to correspond with the 6-h assessment of BOMAC phagocytic activity, ROS production, and gene expression and for $24 \mathrm{~h}$ to a range of concentrations $(0.25,0.5,1,2,4$, and $8 \mathrm{mg} / \mathrm{mL})$ of $S$. cerevisiae CWC from stains A, B, C, and D and 2 forms of dead $S$. cerevisiae strain A to correspond with the 24-h assessment of BOMAC gene expression. The cell culture plates were centrifuged briefly at $200 \times g$ for 3 min to ensure direct interaction between BOMAC and S. cerevisiae $\mathrm{CWC}$ before incubation at $37^{\circ} \mathrm{C}$ with $5 \%$ $\mathrm{CO}_{2}$. After each exposure period, BOMAC were washed with warm PBS 3 times, then incubated with calcein AM $(2 \mu \mathrm{g} / \mathrm{mL}$; Invitrogen, Carlsbad, CA $)$, diluted in culture medium at room temperature for $30 \mathrm{~min}$ to strain live BOMAC. The number of live BOMAC was estimated by measuring the fluorescence intensity (FI) of calcein AM (excitation $494 \mathrm{~nm}$, emission $517 \mathrm{~nm}$ ) using a 1420 Victor2 multilabel counter (Beckman Coulter Inc., Brea, CA). Cell viability was calculated using the formula

$$
\text { cell viability }(\%)=(\mathrm{X} / \mathrm{Y}) \times 100,
$$

where $\mathrm{X}$ is the $\mathrm{FI}$ value in each well containing yeast CWC-treated cells and $\mathrm{Y}$ is the mean value of the FI of all control wells. The concentrations that did not affect the cell viability greater than $5 \%$ were used for further studies (Figure 1). This procedure was repeated 3 times for a total of 3 independent trials, and there were 6 replicates for each treatment within each trial. Similarly, the procedures for assessment of phagocytosis and ROS production were repeated 3 times with 6 replicates in each treatment.

\section{Assessment of BOMAC Phagocytosis of MAP During Exposure to $S$. cerevisiae CWC}

The BOMAC were seeded into black 96 -well flat-bottom plates $\left(5 \times 10^{4}\right.$ cells/well $)$ in culture medium that did not contain amphotericin $\mathrm{B}$ and other antibiotics and were incubated for $17 \mathrm{~h}$ at $37^{\circ} \mathrm{C}$ with $5 \% \mathrm{CO}_{2}$. The cells were then exposed to a range of concentrations of each $S$. cerevisiae CWC $(0.25-4 \mathrm{mg} / \mathrm{mL}$ for strains A, $\mathrm{B}$, and $\mathrm{C}$; $0.25-2 \mathrm{mg} / \mathrm{mL}$ for strain $\mathrm{D} ; 0.25-1 \mathrm{mg} / \mathrm{mL}$ for the dead yeast strain A) simultaneously with MAP at a multiplicity of infection $(10 \mathrm{cfu} / \mathrm{cell})$. The cell culture plates were centrifuged at $200 \times g$ for 3 min to ensure interactions between MAP and BOMAC before incubation at $37^{\circ} \mathrm{C}$ with $5 \% \mathrm{CO}_{2}$ for $6 \mathrm{~h}$. Following this, the plates were washed with warm PBS 3 times, and the uptake of MAP was estimated by measuring the FI of mCherry-MAP (excitation $587 \mathrm{~nm}$, emission $610 \mathrm{~nm}$ ) using a 1420 Victor2 multilabel counter. The amount of phagocytized MAP was calculated for each S. cerevisiae CWC using the formula phagocytized $\mathrm{MAP}=\mathrm{A}-\mathrm{B}$, where $\mathrm{A}$ is the FI value of each well of each $S$. cerevisiae CWC treatment with MAP and B is the mean value of the FI of all wells of the corresponding control group containing the same concentration of S. cerevisiae CWC without MAP.

\section{Assessment of ROS Production Following Exposure to S. cerevisiae CWC}

The BOMAC were seeded into black 96-well flatbottom plates $\left(5 \times 10^{4}\right.$ cells/well $)$ in culture medium that did not contain amphotericin $\mathrm{B}$ and other antibiotics, incubated for $17 \mathrm{~h}$ at $37^{\circ} \mathrm{C}$ with $5 \% \mathrm{CO}_{2}$, and then exposed to a range of concentrations of each $S$. cerevisiae CWC $(0.5-4 \mathrm{mg} / \mathrm{mL}$ for strains $\mathrm{A}, \mathrm{B}$, and C; $0.5-2 \mathrm{mg} / \mathrm{mL}$ for strain $\mathrm{D} ; 0.25-1 \mathrm{mg} / \mathrm{mL}$ for the dead strain A). The cell culture plate was centrifuged at 200 $\times g$ for 3 min before incubation at $37^{\circ} \mathrm{C}$ with $5 \% \mathrm{CO}_{2}$. After a 6-h period, the plates were washed with warm PBS 3 times, incubated with $100 \mu \mathrm{L} /$ well of CellRox Green reagent (Invitrogen) at $37^{\circ} \mathrm{C}$ with $5 \% \mathrm{CO}_{2}$ for 1 $\mathrm{h}$, and again washed with warm PBS. The production of ROS was estimated using a 1420 Victor2 multilabel counter by measuring the fluorescence of the CellROX Green reagent (excitation $485 \mathrm{~nm}$, emission $520 \mathrm{~nm}$ ).

\section{Real-Time PCR Quantification of BOMAC Gene Expression Following Exposure to S. cerevisiae CWC}

Cell Preparation and Exposure to $S$. cerevisiae CWC, Total RNA Isolation, and cDNA Synthesis. The BOMAC were seeded at $0.5 \times 10^{6} /$ well into 6 -well flat-bottom plates (Corning) and incubated for $17 \mathrm{~h}$ at $37^{\circ} \mathrm{C}$ with $5 \% \mathrm{CO}_{2}$. The cells then were exposed to a range of concentrations of yeast CWC $(0.25,0.5$, 1,2 , and $4 \mathrm{mg} / \mathrm{mL}$ for strains $\mathrm{A}$ and $\mathrm{B} ; 0.25-8 \mathrm{mg} / \mathrm{mL}$ 

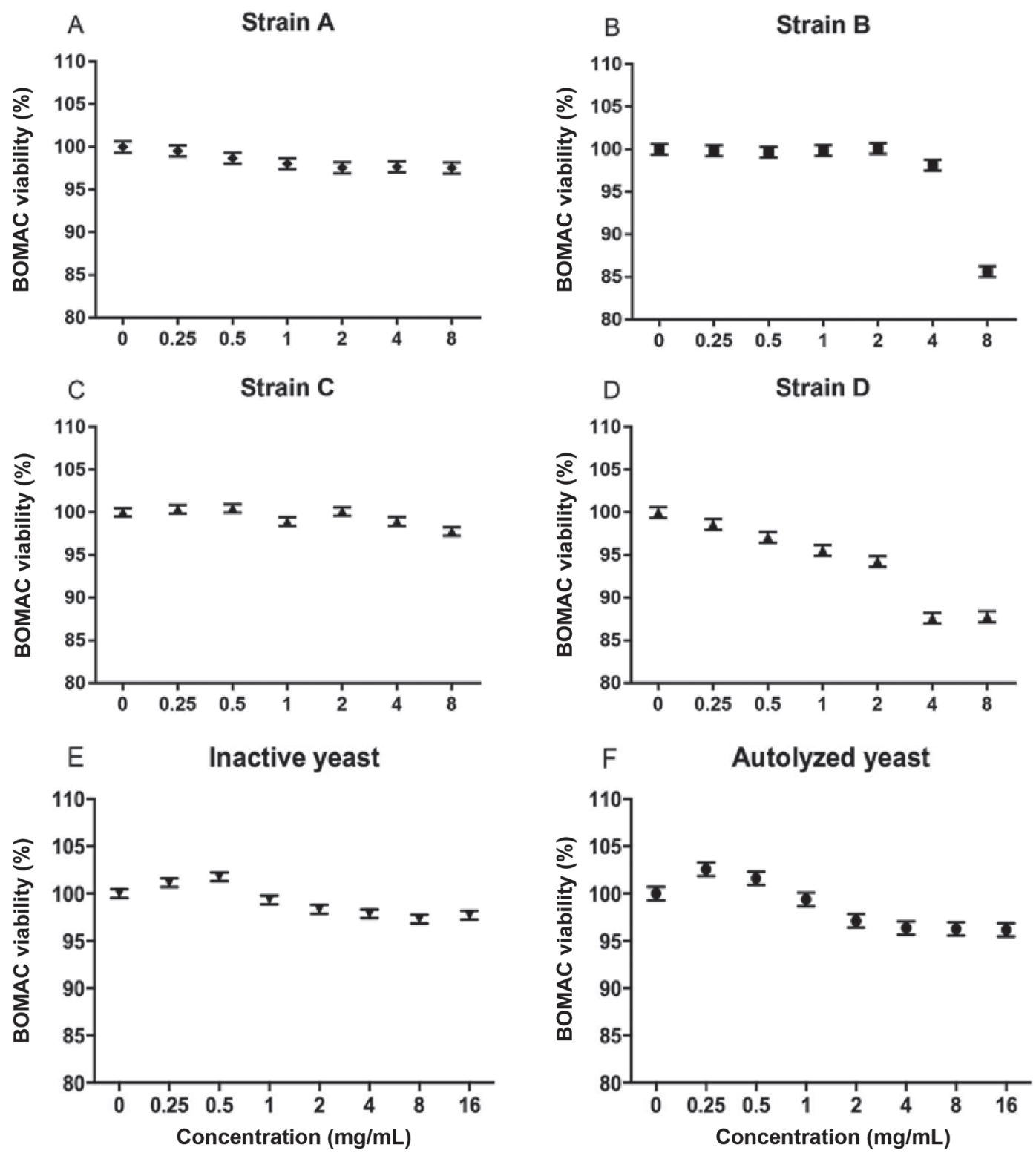

Figure 1. Viability of bovine macrophage cell lines (BOMAC) following 6-h exposure to cell wall components from yeast strains A (A), B (B), C (C), and D (D) and to 2 forms of dead yeast from strain A [inactive yeast (E); autolyzed yeast (F)]. Data are presented as LSM \pm SE.

for strain $\mathrm{C}$; $0.25-2 \mathrm{mg} / \mathrm{mL}$ for strain $\mathrm{D}$; and $0.25-1$ $\mathrm{mg} / \mathrm{mL}$ for the dead yeast strain A). A control group that did not contain yeast CWC was also included. For all treatments, the cells were incubated for 6 and 24 $\mathrm{h}$, respectively. Gene expression was assessed at $6 \mathrm{~h}$ to coincide with the assessment of macrophage functions (i.e., viability, phagocytosis of MAP, and ROS production) and at $24 \mathrm{~h}$ to assess potential changes in immune regulation (i.e., inflammatory vs. anti-inflammatory cytokine expression and expression of cytokines driving T-helper cell differentiation and tissue repair). The plates were washed with PBS and then lysed using $1 \mathrm{~mL}$ of TRIzol (Invitrogen) per well. The cell lysates were aliquoted into $2.0-\mathrm{mL}$ nuclease-free cryogenic vials and stored at $-80^{\circ} \mathrm{C}$ for later RNA isolation (Invitrogen) according to the manufacturer's protocol. The exposure trials were repeated 3 times, and the extraction was conducted separately for each trial.

Total RNA concentration was measured using a NanoDrop ND-8000 spectrophotometer (Thermo Fisher Scientific, Waltham, MA). The RNA integrity number, which is a standard to evaluate the degree of RNA degradation for conducting valid gene expression measurement experiments (Schroeder et al., 2006), was 
assessed using an Agilent 2100a bioanalyzer (Agilent Technologies, Santa Clara, CA). The RNA integrity numbers from all samples were higher than 7 , indicating high-quality RNA from all samples. Total RNA (5 $\mu \mathrm{g})$ was reverse transcribed to cDNA using oligo-dT primers and Superscript III reverse transcriptase (Invitrogen) according to the manufacturer's instructions.

Primer Design and Real-Time PCR Quantification. The primers were designed based on the Bos taurus sequences extracted from GenBank using the Primer3 software (http://bioinfo.ut.ee/primer3-0.4.0/). All primer sequences and relevant information about the genes are presented in Table. 1. Target gene expression was evaluated by semiquantitative real-time PCR (qPCR) using an ABI Prism 7000 sequence detection system (Applied Biosystems, Burlington, ON, Canada). The qPCR was performed in a $25-\mu \mathrm{L}$ reaction containing $1 \mu \mathrm{L}$ of cDNA $(15 \mathrm{ng} / \mu \mathrm{L}), 12.5 \mu \mathrm{L}$ of PerfeCTa SYBR Green SuperMix, Rhodamine X (ROX, Quanta BioSciences, Gaithersburg, MD), and $400 \mathrm{n} M$ of each primer. The qPCR running protocol was $50^{\circ} \mathrm{C}$ for 3 min, $95^{\circ} \mathrm{C}$ for $5 \mathrm{~min}$, and 40 cycles of denaturation at $95^{\circ} \mathrm{C}$ for $15 \mathrm{~s}$, annealing temperatures for $30 \mathrm{~s}$ (Table 1 ), and extension at $72^{\circ} \mathrm{C}$ for $30 \mathrm{~s}$. A dissociation curve was performed following each $\mathrm{qPCR}$ reaction to ensure the presence of a uniform and single PCR product.

The cycle threshold $(\mathbf{C t})$ values for each sample were determined using the auto $\mathrm{Ct}$ function of the ABI Prism 7000 SDS software (Applied Biosystems). Each cDNA sample from each trial was run in quadruplicate for each gene, and the mean of $\mathrm{Ct}$ values from those quadruplicate samples was used to calculate the quantity of PCR product by standard curve analysis (Rutledge and Cote, 2003). Specifically, Ct values were transformed into units defined by standard curve, and then the transformed values of target genes were divided by that of GAPDH to generate normalized values, which later were log-transformed and processed using SAS (SAS Institute Inc., Cary, NC) for statistical analysis. Gene-specific standard curves were generated using pooled cDNA and run on each plate. The 2 candidate reference genes that were included in the present study were GAPDH and $\beta$-actin; GAPDH was selected based on its stability across treatments, and it was used to normalize the expression of the following target genes that were chosen with regard to their immunoregulatory properties: IL6, IL10, IL12p40,IL13, IL23, TGFB, $A R G 1, C A S P 1$, and $i N O S$.

\section{Statistical Analysis}

The BOMAC viability was analyzed as a randomized complete block design in which the 3 independent trials represented the random blocks in each analysis. The model included blocks as a random effect and $S$. cerevisiae CWC and concentration plus their interactions as fixed effects. Separate residual variances for each $S$. cerevisiae CWC were incorporated in the model. The MIXED procedure of SAS 9.4 (SAS Institute Inc.) was used, and the linear and quadratic orthogonal polyno-

Table 1. Summary of oligonucleotide primer sequences used for PCR, product size, and annealing temperature

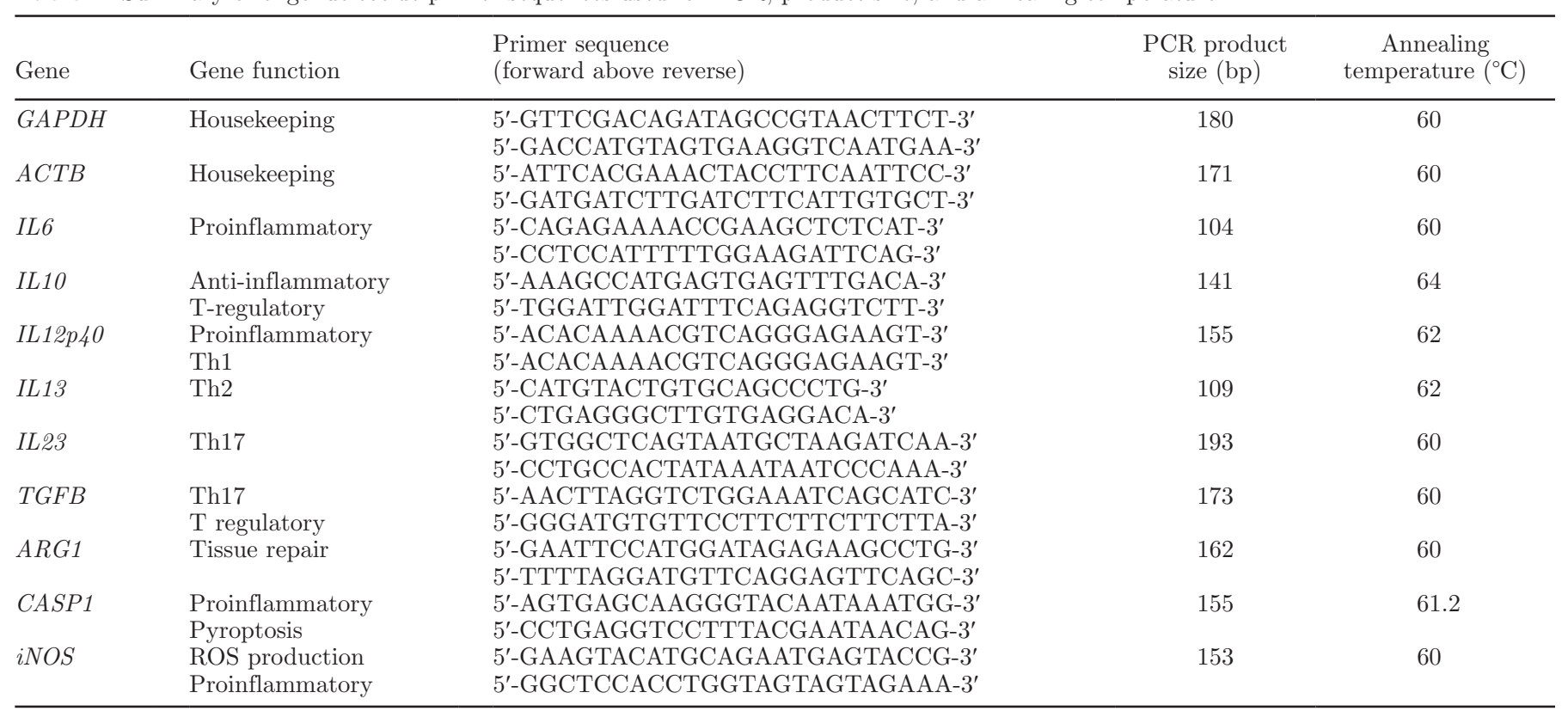


mial contrasts across S. cerevisiae CWC concentration were used to assess changes in viability over concentration.

The BOMAC phagocytic activity, ROS production, and gene expression data were analyzed separately as a randomized complete block design study with 3 independent trials representing each block. All data, including florescent intensity of mCherry-MAP and ROS as well as Ct values, were log-transformed before analysis to stabilize variances. The MIXED procedure of SAS 9.4 was used to generate least squares means and standard error, and normality of the data was ensured by examining the residual plots. Dunnett's test was then applied for statistical significance in concentrationdependent responses between control and treatments by a 1 -way ANOVA.

Graphs were generated using GraphPad Prism version 4.00 (GraphPad Software, San Diego, CA), and all data were presented as least squares means of the $\log$-transformed data \pm standard error. A $P$-value of $\leq 0.05$ was considered statistically significant.

\section{RESULTS}

\section{Effect of S. cerevisiae CWC on BOMAC Viability}

The BOMAC viability was significantly reduced at 6 $\mathrm{h}$ by $S$. cerevisiae $\mathrm{CWC}$ from stains $\mathrm{A}, \mathrm{B}, \mathrm{C}$, and $\mathrm{D}$ as indicated by linear contrasts $(P<0.01)$ and by both forms of dead $S$. cerevisiae strain A as indicated by quadratic contrasts $(P<0.01$; Figure 1$)$. The BOMAC viability was not significantly affected by exposure to $S$. cerevisiae components at concentrations that were selected to assess BOMAC 24-h gene expression (data not shown).

\section{Effect of S. cerevisiae CWC on BOMAC Phagocytosis of MAP}

Saccharomyces cerevisiae CWC from all strains reduced MAP uptake by BOMAC under cocultured conditions for $6 \mathrm{~h}$ at all tested concentrations (Figure 2A-D; $P<0.05)$. Similarly, the number of MAP phagocytized by BOMAC appeared to decrease as the concentration of both forms of dead strain A increased. A significant reduction can be seen at $0.25 \mathrm{mg} / \mathrm{mL}$ and above for the inactive yeast (Figure $2 \mathrm{E}$ ) and at $0.5 \mathrm{mg} / \mathrm{mL}$ and above for the autolyzed yeast $(P<0.05$; Figure $2 \mathrm{~F})$.

\section{Effect of S. cerevisiae CWC on ROS Production by BOMAC}

A significant increase in ROS production by BOMAC was observed at all tested concentrations of $S$. cerevisiae
CWC from strains A, C, and D (Figure 3A, C, and D) after the 6-h exposure period. Similarly, a significant concentration-dependent increase in ROS production was observed at $1 \mathrm{mg} / \mathrm{mL}$ and higher for $S$. cerevisiae CWC from strain B (Figure 3B). Additionally, the 2 forms of dead S. cerevisiae significantly induced ROS production by BOMAC in a concentration-dependent manner during the 6-h exposure period at all tested concentrations (Figure 3E and F).

\section{Effect of S. cerevisiae CWC on BOMAC Immune-Related Gene Expression}

The effect of $S$. cerevisiae $\mathrm{CWC}$ on the relative expression of genes responsible for modulating immune function was evaluated with BOMAC using GAPDH as the reference (Tables 2, 3, and 4). At $6 \mathrm{~h}$, the expression of $I L 6$ was significantly induced $(P<0.05)$ by $S$. cerevisiae CWC from strain A at 2 and $4 \mathrm{mg} / \mathrm{mL}$; strain B at 1,2 , and $4 \mathrm{mg} / \mathrm{mL}$; strain $\mathrm{C}$ at 0.5 and $4 \mathrm{mg} / \mathrm{mL}$; strain D at $0.5,1$, and $2 \mathrm{mg} / \mathrm{mL}$; and the autolyzed $S$. cerevisiae strain A at $0.5 \mathrm{mg} / \mathrm{mL}$. The expression of $I L 10$ was significantly lower $(P<0.05)$ at 1 and $8 \mathrm{mg} / \mathrm{mL}$ exposure of CWC from strain C than in the control group. The expression of IL13 was significantly decreased $(P<0.05)$ by CWC from strain A at $0.25 \mathrm{mg} / \mathrm{mL}$ but increased by CWC from strain $\mathrm{B}$ at 2 and $4 \mathrm{mg} / \mathrm{mL}$. The expression of IL23 was significantly induced $(P<0.05)$ by $\mathrm{CWC}$ from strain $\mathrm{C}$ at $8 \mathrm{mg} / \mathrm{mL}$. The expression of $A R G 1$ was significantly increased $(P<0.05)$ by the exposure to CWC from both forms of dead yeast at $0.5 \mathrm{mg} / \mathrm{mL}$. The expression of $C A S P 1$ was significantly lower $(P<0.05)$ within the treatment of CWC from strain A at $0.5 \mathrm{mg} / \mathrm{mL}$ and strain B at 0.25 and $0.5 \mathrm{mg} / \mathrm{mL}$ than in the control group. In contrast, caspase 1 was significantly induced $(P<0.05)$ by inactive yeast $(0.25,0.5$, and $1 \mathrm{mg} / \mathrm{mL})$ and autolyzed yeast $(0.5 \mathrm{mg} / \mathrm{mL})$. The expression of iNOS was significantly reduced $(P<0.05)$ by CWC only from strain $\mathrm{C}$ at $1,2,4$, and $8 \mathrm{mg} / \mathrm{mL}$. The expression of IL12p 40 and TGFB were not significantly affected by yeast CWC from all the strains and both forms of dead yeast strain A.

At $24 \mathrm{~h}$, there was a significant increase $(P<0.05)$ in the expression of $I L 6$ following treatment with CWC from strain $\mathrm{C}$ at $8 \mathrm{mg} / \mathrm{mL}$ as well as that of IL- 10 within treatment with CWC from strain D at $2 \mathrm{mg} / \mathrm{mL}$ and IL12p 40 within the treatment with CWC from strain B at $4 \mathrm{mg} / \mathrm{mL}$, strain $\mathrm{C}$ at 0.25 and $1 \mathrm{mg} / \mathrm{mL}$, and strain $\mathrm{D}$ at $2 \mathrm{mg} / \mathrm{mL}$. The expression of $I L 13$, in contrast, was significantly reduced $(P<0.05)$ by CWC from strain A at $0.25 \mathrm{mg} / \mathrm{mL}$ but significantly increased at $4 \mathrm{mg} / \mathrm{mL}$; increased IL13 expression $(P<0.05)$ was also observed in response to CWC from strain B at $0.5,2$, and $4 \mathrm{mg} /$ 
$\mathrm{mL}$ and strain $\mathrm{D}$ at $2 \mathrm{mg} / \mathrm{mL}$. A significant reduction $(P<0.05)$ in the expression of IL23 occurred in response to CWC from strain A at $0.5 \mathrm{mg} / \mathrm{mL}$; however, the expression of IL23 was significantly induced $(P<$ 0.05 ) by CWC from both strain $\mathrm{A}$ and $\mathrm{B}$ at $4 \mathrm{mg} / \mathrm{mL}$ as well as treatment with CWC from strains $\mathrm{C}(0.5,1$, $2,4$, and $8 \mathrm{mg} / \mathrm{mL})$ and $\mathrm{D}(2 \mathrm{mg} / \mathrm{mL})$ and autolyzed yeast at $0.25 \mathrm{mg} / \mathrm{mL}$. A similar result was observed for $T G F B$ expression, with decreased expression $(P<$ $0.05)$ occurring in response to $\mathrm{CWC}$ from strain $\mathrm{A}$ at
$0.5 \mathrm{mg} / \mathrm{mL}$ but increased expression $(P<0.05)$ occurring in response to CWC from strain $\mathrm{B}$ at $4 \mathrm{mg} / \mathrm{mL}$ as well as CWC from strain $\mathrm{C}$ at all tested concentrations and strain D at $2 \mathrm{mg} / \mathrm{mL}$. Significant increases $(P<$ $0.05)$ in $A R G 1$ were observed in response to CWC from all the strains, whereas decreases were seen in both forms of dead yeast. There was a significant increase $(P$ $<0.05)$ in $C A S P 1$ expression upon exposure to strain $\mathrm{A}$ at $0.5 \mathrm{mg} / \mathrm{mL}$ and strain $\mathrm{B}$ at $0.5,1$, and $4 \mathrm{mg} / \mathrm{mL}$ as well as to autolyzed yeast at $0.25 \mathrm{mg} / \mathrm{mL}$. Finally,
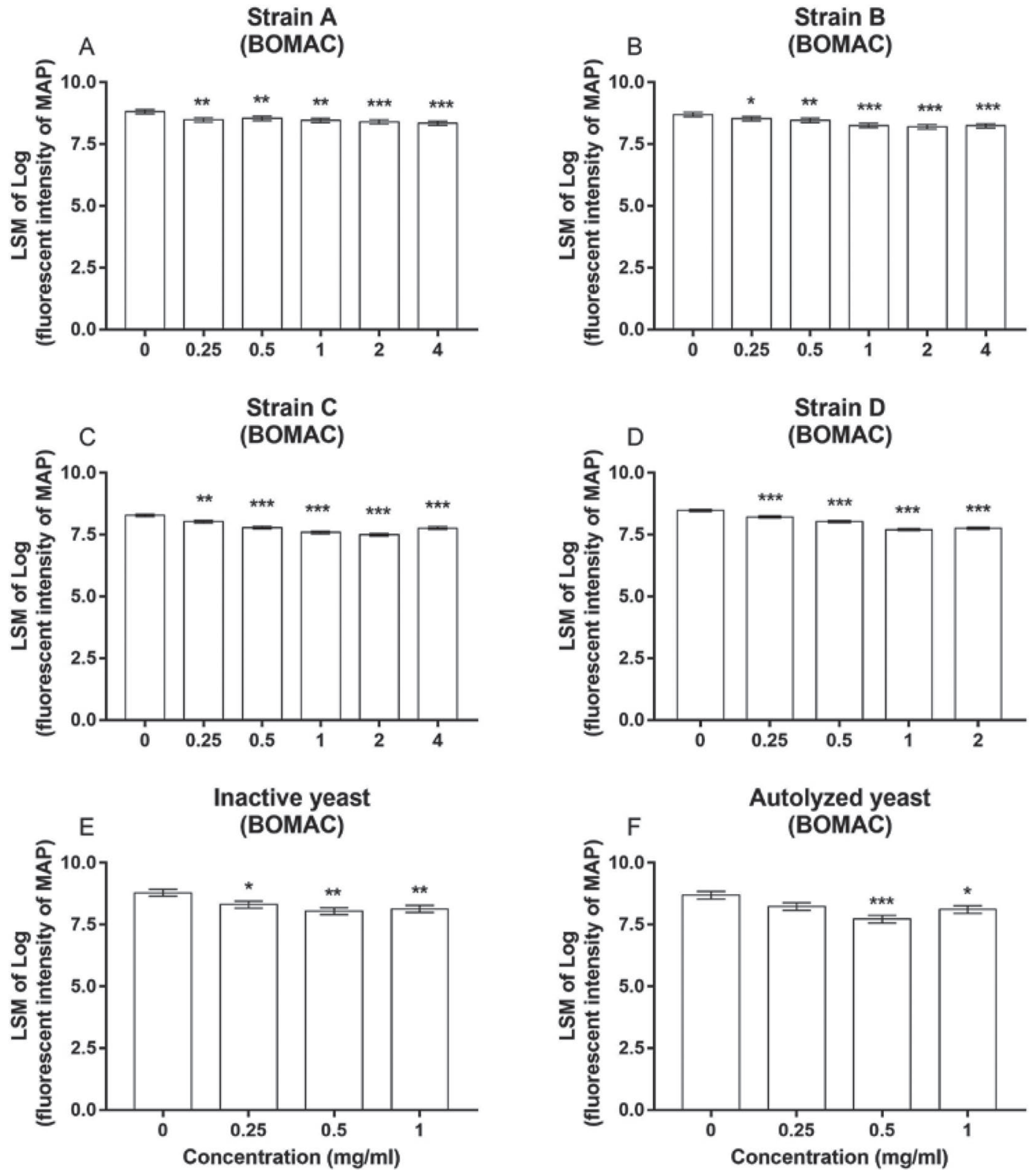

Figure 2. Bovine macrophage cell lines (BOMAC) phagocytosis of Mycobacterium avium ssp. paratuberculosis MAP in the presence of yeast cell wall components from strains A (A), B (B), C (C), and D (D) and 2 forms of dead yeast from strain A inactive yeast (E); autolyzed yeast $(\mathrm{F})$ ] after 6-h exposure. Significant differences relative to the control are indicated at $P<0.05(*), 0.01(* *)$, and $0.001(* * *)$. Data are presented as $\mathrm{LSM} \pm \mathrm{SE}$. 
the expression of $i N O S$ was significantly reduced $(P$ $<0.05$ ) by treatment with strain $\mathrm{A}$ at $2 \mathrm{mg} / \mathrm{mL}$ and inactive yeast at $0.5 \mathrm{mg} / \mathrm{mL}$.

\section{DISCUSSION}

Several studies have demonstrated that yeast components are potent immunostimulants in fish species (Jha et al., 2007; Kunttu et al., 2009; Andrews et al., 2011). In addition, yeast components have been shown to have effects on the immune response in pigs by increasing leucocyte counts and cytokine IL-18 secretion compared with nonsupplemented pigs (Ganner et al., 2010; Zhou et al., 2013). However, the immunomodulating effect of yeast components on ruminants has not been extensively investigated. The present study contributes to this research field by demonstrating that BOMAC function, including BOMAC phagocytic activity, ROS production, and immune-related gene expression, is altered by S. cerevisiae components. The BOMAC were used in this study because of ease of culture and high throughput potential for screening bioactive compounds, and
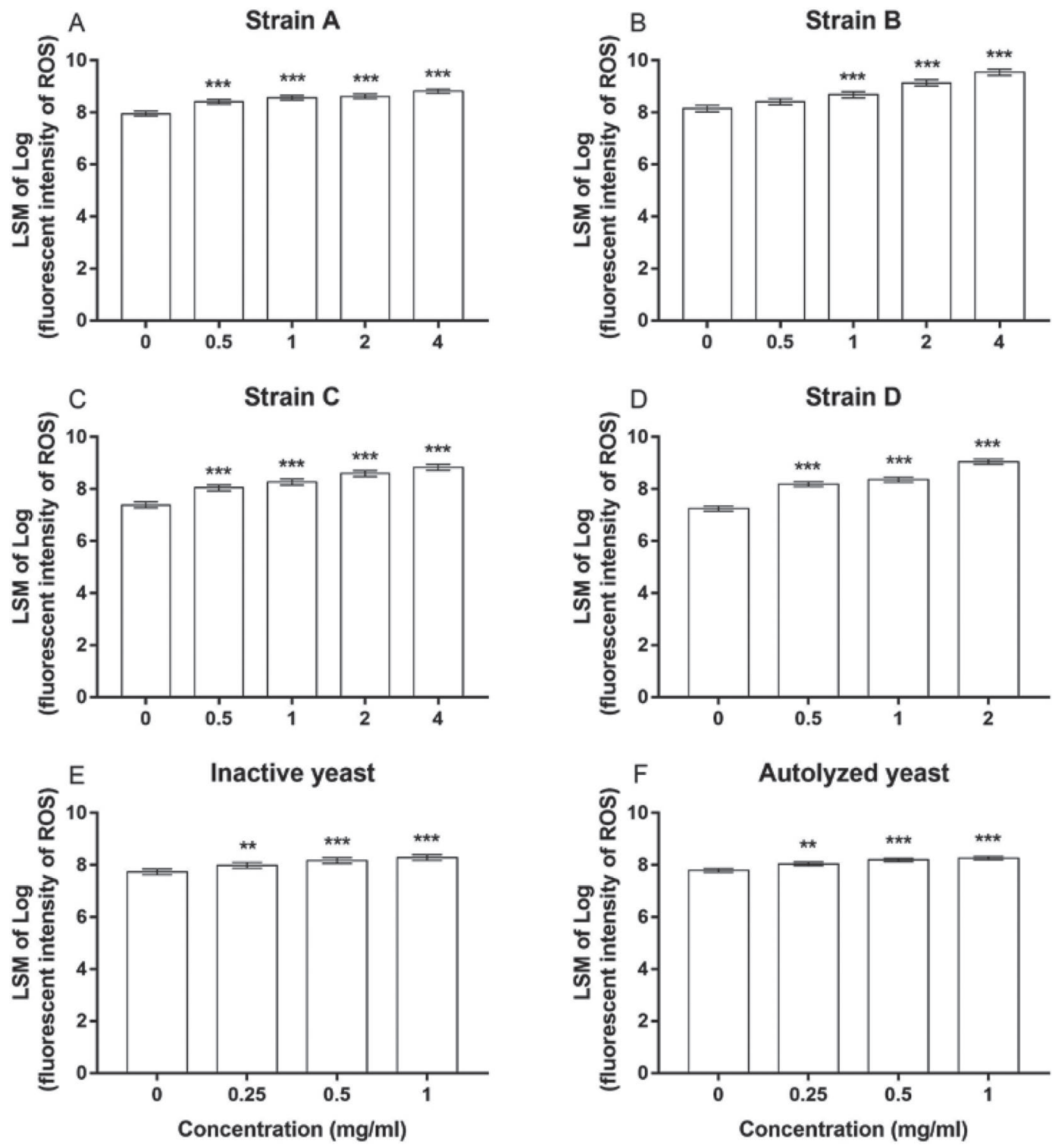

Figure 3. Reactive oxygen species (ROS) production in bovine macrophage cell lines in the presence of yeast cell wall components from strains A (A), B (B), C (C), and D (D) and 2 forms of dead yeast from strain A [inactive yeast (E); autolyzed yeast (F)] after 6-h exposure. Significant differences relative to the control are indicated at $P<0.05(*), 0.01(* *)$, and $0.001(* * *)$. Data are presented as LSM \pm SE. 
IMMUNOMODULATORY ACTIVITY OF YEAST COMPONENTS

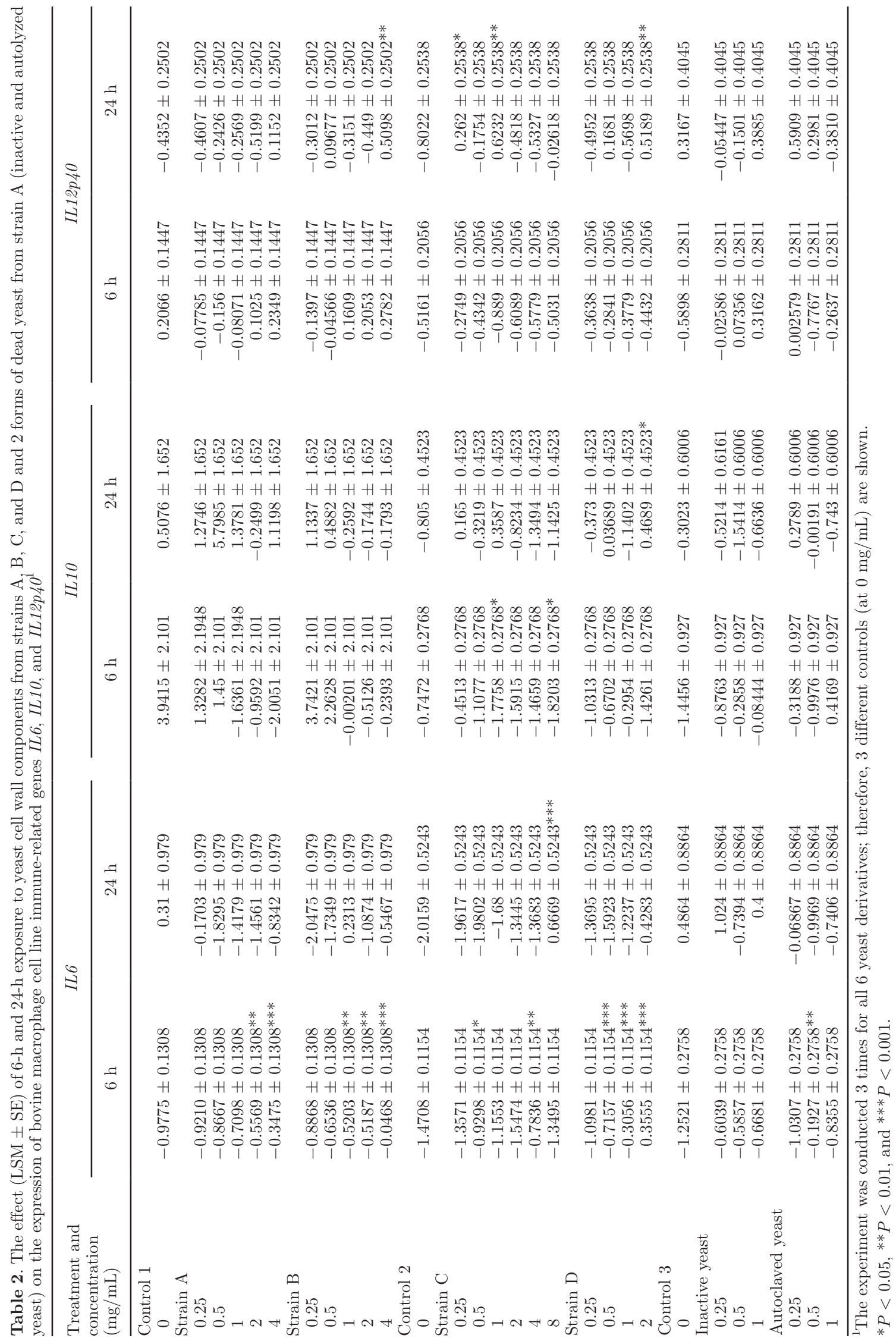




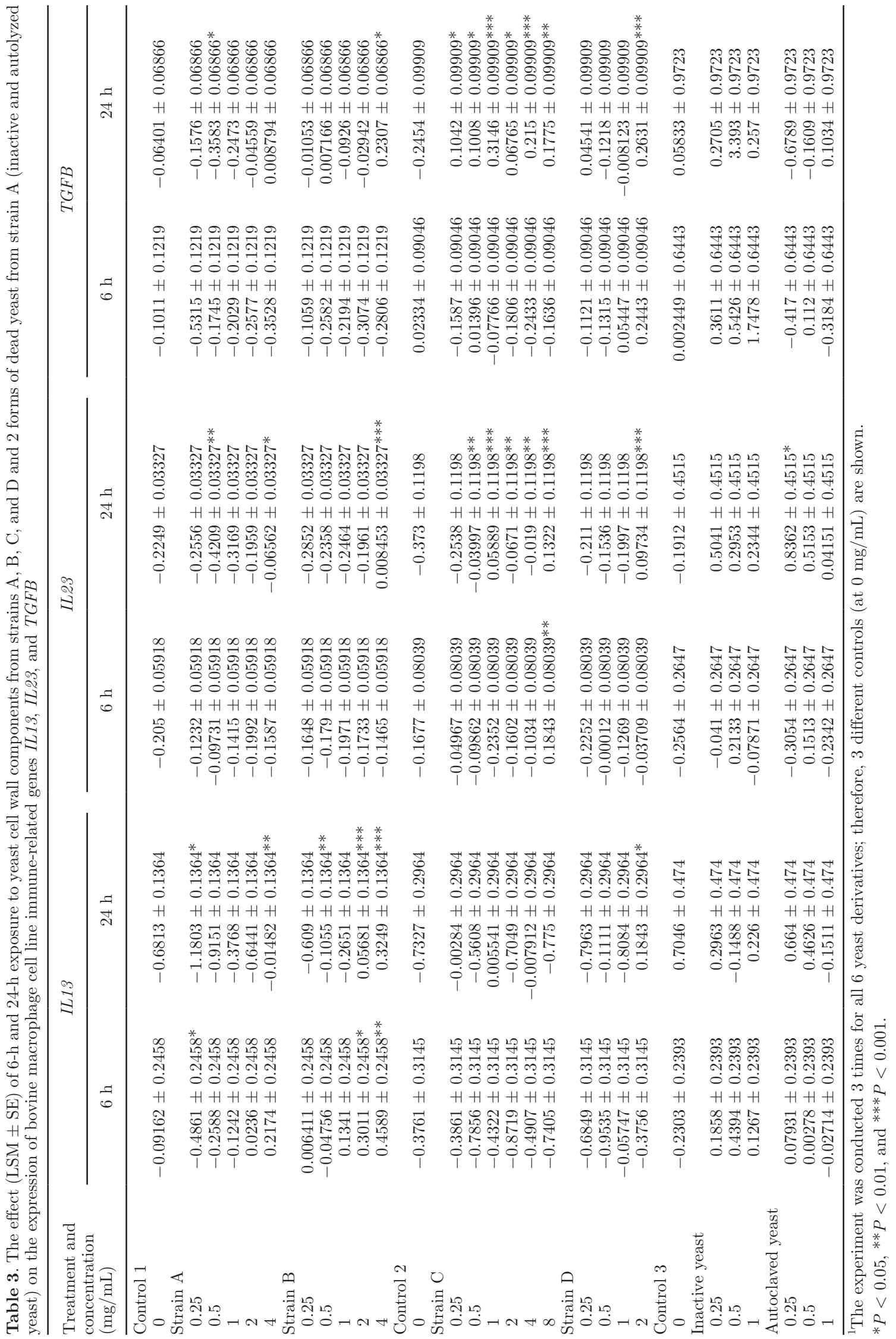




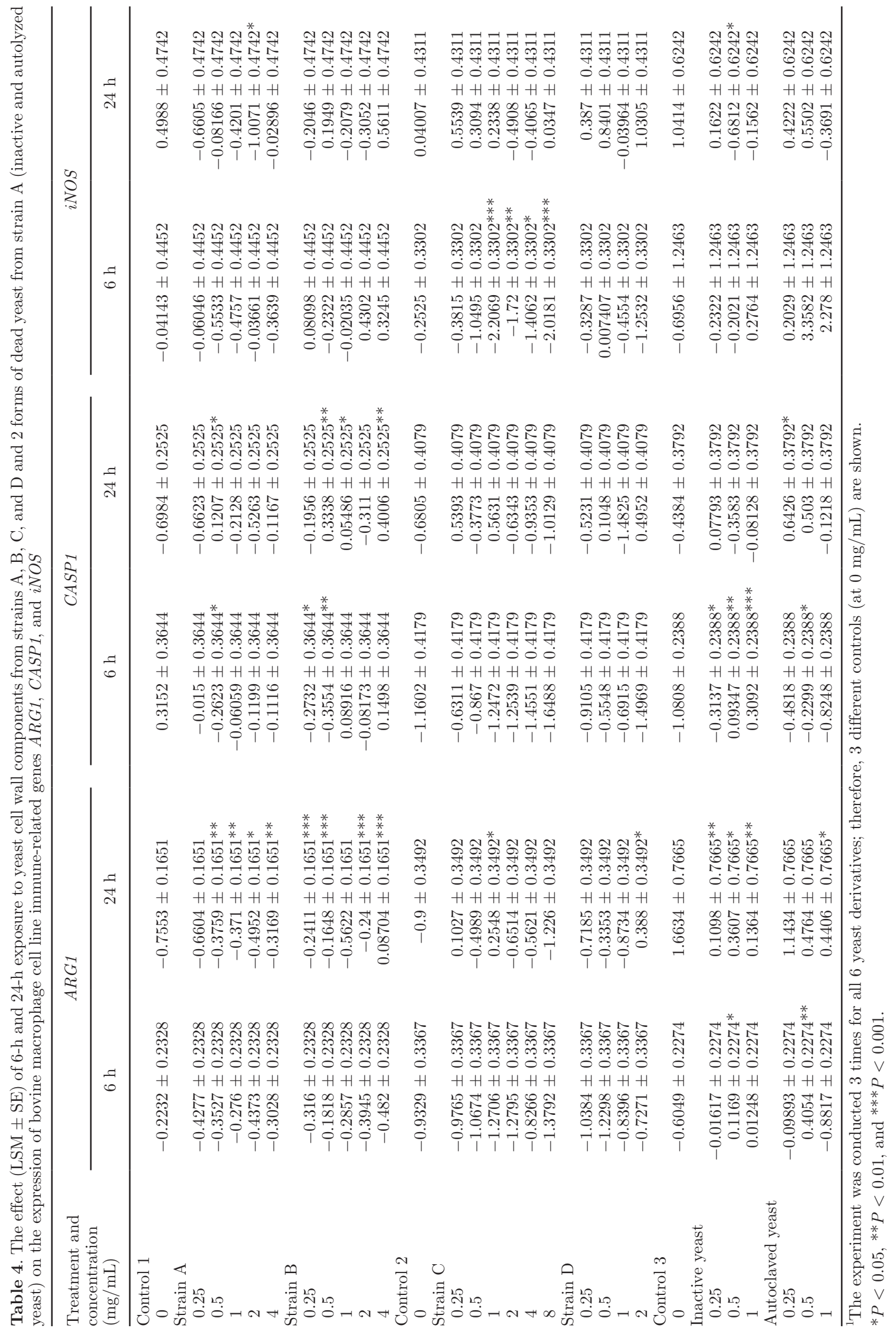


their uniformity allows for better control of variation that is characteristic to primary macrophages within and across animals.

One concern with using BOMAC was that yeast components may alter macrophage viability. Therefore, BOMAC viability was tested after 6 -h and 24 -h exposure periods to correspond with the functional assays used in this study. Although significant changes in cell viability were detected, only CWC from strains B and D reduced cell viability below $95 \%$ at the concentrations tested in this study. The decrease in cell viability associated with CWC from strains B and D might be related to changes in intracellular homeostasis and apoptosis-regulated gene expression. Higher concentrations of yeast components may induce cell apoptosis via altering intracellular calcium levels and the ratio of Bax and Bcl-2, as was demonstrated in human breast cancer cells exposed to heat-killed S. cerevisiae (Ghoneum et al., 2008). The genes Bax and $B c l 2$ are 2 discrete members of a gene family involved in the regulation of cellular apoptosis; Bax protein is known as an apoptosis-promoting factor, whereas Bcl-2 protein is an apoptosis-suppressing factor (Hockenbery et al., 1990; Oltvai et al., 1993; Yang and Korsmeyer, 1996). A significant reduction of cell viability was also seen in our previous study using bovine epithelial cells; however, CWC from strains B and D appear to reduce the viability of bovine epithelial cells to a greater degree than BOMAC (Li et al., 2016). Future studies are needed to explore how CWC from strains B and D affected cell viability.

It was interesting to note that a higher percentage of viable BOMAC was observed in treatments containing both forms of dead yeast from strain A at lower concentrations $(0.25$ and $0.5 \mathrm{mg} / \mathrm{mL})$ but not in the CWC treatments. Because the dead forms of yeast strain A are more crude components than the CWC, it is possible that these changes reflected increased cell proliferation caused by yeast cellular components no longer present in the CWC. We also observed this response when 2 different types of epithelial cells were exposed to inactive yeast ( $\mathrm{Li}$ et al., 2016).

Phagocytic activity of BOMAC was also significantly affected by exposure to the yeast components, with a maximum reduction of MAP phagocytized by BOMAC ranging from 5 to $8 \%$. It is possible that reduced cell viability may have confounded results at higher concentrations; however, we do not believe this to be the case because phagocytosis was also reduced at lower concentrations where viability was unaffected. Previously, we demonstrated that these same yeast components reduced MAP binding to bovine epithelial cells (Li et al., 2016); thus, it is possible that similar interac- tions occur with phagocytic cells such as macrophages and dendritic cells. Another possible explanation for this observation is that the macrophage's capacity to phagocytize MAP may be reduced by uptake of yeast components because $S$. cerevisiae is also phagocytized by macrophages (Seif et al., 2016). Given that MAP has been reported to target, survive, and replicate within macrophages (Kuehnel et al., 2001; Pieters, 2001), reduced phagocytosis of MAP by macrophages and other phagocytic cells might be beneficial for reducing the risk of MAP infection. Collectively, results from this study and the Li et al. (2016) study support the use of supplements containing yeast components to reduce risk of MAP infection across the gut epithelial barrier.

The present study also showed that $S$. cerevisiae components induced ROS production by BOMAC. Because these cytolytic ROS cause phagosome acidification that leads to the activation of numerous antimicrobial enzymes, ROS represent an important arsenal for destroying intracellular pathogens such as Mycobacteria spp. (Ehrt and Schnappinger, 2009). Reactive oxygen species can also induce host cell apoptosis (Dumont et al., 1999); thus, it is possible that the reduced BOMAC viability observed at the highest $\mathrm{CWC}$ concentrations from strains B and D was attributed, in part, to the generation of ROS.

Induction of ROS by yeast components is well documented. Yeast $\beta$-glucans, for example, have been previously shown to induce human neutrophil and monocyte ROS production (Vetvicka et al., 1996; Rubin-Bejerano et al., 2007), and increased ROS production was also observed when human whole blood was preincubated with poly-[1-6]-D-glucopyranosyl-[1-3]-D-glucopyranose-glucan derived from the cell wall of $S$. cerevisiae (Wakshull et al., 1999). In vivo, dietary supplementation with $\beta$-glucans was also shown to induce macrophage ROS production in the Asian catfish (Kumari and Sahoo, 2006) and the zebrafish species (Rodríguez et al., 2009).

It has previously been demonstrated that yeast $\beta$-glucans interact with a lectin-like moiety on dectin-1 (Willment et al., 2001). Dectin-1 is a transmembrane pattern-recognition receptor on macrophages (Brown et al., 2003) that initiates phagocytosis and generation of inflammatory mediators, such as ROS, in association with TLR2 (Brown et al., 2003). Although it is beyond the scope of the present study, future studies could use a dectin-1 antagonist to investigate the involvement of dectin-1 in ROS production by these yeast components.

It should be noted that in the present study, BOMAC ROS production and phagocytosis were assessed as separate assays; this precludes us from determining the biological significance of yeast derivative-induced ROS 
production in the context of Johne's disease. Although phagocytosis of MAP was significantly reduced by the yeast components, BOMAC were still capable of carrying out phagocytosis; increased ROS production by these cells could help destroy intracellular MAP. To test this hypothesis, future studies could consider simultaneously measuring ROS production in macrophages that phagocytosed MAP as well as assess MAP viability in these cells.

The expression of BOMAC genes coding different immune-related cytokines was also altered in this study by the various yeast components. Cytokine genes regulating inflammation, for example, were differentially affected. The proinflammatory cytokine IL-6 gene was significantly induced by exposure to CWC from all strains and autolyzed yeast. This is in agreement with a study by Volman et al. (2008), who showed that IL-6 expression was increased when human whole blood was incubated with $\beta$-glucans derived from $S$. cerevisiae. Because IL-6 is an important inducer of the acutephase response (Akira et al., 1990) and modulates Tcell and B-cell activation and proliferation, increased IL-6 production may augment the adaptive immune system (Van Seventer et al., 1991).

Constitutive expression of proinflammatory caspase 1 was also differentially affected by the yeast components. Expression of $C A S P 1$ was inhibited during early stimulation by CWC from strains $\mathrm{A}$ and $\mathrm{B}$, whereas $C A S P 1$ expression was induced by autolyzed yeast and inactive yeast during early stimulation and by CWC from strains A and B during late stimulation. Studies relating to the altered expression of caspase 1 following the direct stimulation of $S$. cerevisiae are rare. Heatkilled $S$. cerevisiae and the purified zymosan and mannan induced caspase 1 and IL-1 $\beta$ secretion in murine bone marrow-derived macrophages when combined with a second stimulus (Lamkanfi et al., 2009); IL-1 $\beta$ bioactivation within the inflammasome is dependent on caspase 1 (Yu and Finlay, 2008). The immunomodulatory implications of these changes in caspase $1 \mathrm{ex}-$ pression in response to $S$. cerevisiae components can be explored in future studies by assessing caspase 1 and IL-1 $\beta$ protein expression, caspase 1 activity, and inflammasome assembly (van de Veerdonk et al., 2009).

Anti-inflammatory IL 10 was also differentially affected by the yeast components. Reduced IL10 expression, for example, was observed by treatment of CWC from strain $\mathrm{C}$ after $6 \mathrm{~h}$, whereas significant induction was observed at $24 \mathrm{~h}$ following the exposure to CWC from strain D. An important study by Jawhara et al. (2012) showed that $S$. cerevisiae and its components can possess anti-inflammatory properties, such as induced IL10 expression, or proinflammatory properties depending on the yeast strain and the preparation process used to purify CWC.

The expression of BOMAC genes coding important immunoregulatory cytokines was also altered in this study by the various yeast components, and this could affect the acquired immune response. For example, significant induction of IL12p40 expression, which is important for driving T-helper cell (Th) 1 differentiation, was detected following treatment with CWC from strains B, C, and D at $24 \mathrm{~h}$. Other studies have also shown that $\beta$-glucans stimulate production of macrophage IL-12p40 (Gantner et al., 2003; Rogers et al., 2005; Ellertsen et al., 2006), which promotes cellmediated immunity against Mycobacterium spp. For example, IL-12p40 deficient mice were more susceptible to chronic mycobacterial infection, and a higher rate of mortality was observed after pulmonary infection with M. tuberculosis (Hölscher et al., 2001).

The expression of several cytokines involved in driving Th17 cell differentiation was also affected in the present study by various yeast components; Th17 cell differentiation depends on the presence of TGF- $\beta$, IL-6, and IL-23 (Dubin and Kolls, 2008). Most interesting, CWC from stain $\mathrm{C}$ induced all 3 of these cytokines. Ligand binding with dectin-1 has been suggested to preferentially induce IL-17 production by Th17 cells in both humans and mice (Palm and Medzhitov, 2007). Increased IL-23 secretion by dendritic cells was reported after stimulation with a fungal CWC (LeibundGutLandmann et al., 2007), and our results are consistent with observations using mice macrophages and dendritic cells stimulated with zymosan (Dillon et al., 2006). Also, Th17 cells have been shown to be associated with increased protection of mice against Mycobacteria challenge (Khader et al., 2007). In the present study, reduced expression of both IL23 and TGFB was also observed due to the exposure to lower concentrations of yeast components from strain A. We were unable to find any research to support this observation, and further experiments will be needed, including assessment of protein expression, to explore this in more detail.

The expression of IL13, which is involved in driving Th2 cell differentiation, was significantly induced in the present study by CWC from strain B at 6 and $24 \mathrm{~h}$. Because IL-13 promotes immunoglobulin synthesis, which is an important effector response against extracellular pathogens, a Th2 response has historically not been considered to be effective against Mycobacterium spp.; this dogma, however, has been convincingly challenged in recent years (Achkar and Casadevall, 2013).

Interleukin-13 also contributes to the polarization of M2 macrophages (alternatively activated macrophages), which are involved in tissue repair and 
remodeling (Gordon, 2003; Gordon and Martinez, 2010). Macrophage polarization appears to be critical for effective immunity to Mycobacterium spp. Macrophage transformation from classically activated (M1) macrophages to M2 macrophages, for example, was found to occur in vitro during Mycobacterium tuberculosis infection, and M2 macrophages were found to predominate in both necrotic and nonnecrotic granulomas obtained from tuberculosis patients (Huang et al., 2015). Macrophage polarization has also been studied in the context of subclinical MAP infection (Thirunavukkarasu et al., 2015); however, the contribution of M1/M2 macrophages to resistance or susceptibility to MAP infection remains to be determined. In the context of $S$. cerevisiae, it was recently demonstrated that phagocytosis of live $S$. cerevisiae skewed macrophage polarization to an M1 phenotype (Seif et al., 2016); however, in the present study, we found no convincing evidence of this occurring in BOMAC in response to the yeast components. For example, although increased IL13, TGFB, and ARG1 expression was observed in BOMAC that were stimulated with CWC from strain $\mathrm{B}$, corresponding decreases in BOMAC IL10 and iNOS were not observed at $24 \mathrm{~h}$; these genes are associated, respectively, with M2 and M1 macrophage polarization (Gordon and Martinez, 2010). Also, increased IL13 and ARG1 and decreased iNOS expression were detected in BOMAC that were stimulated with CWC strain $\mathrm{A}$ at $24 \mathrm{~h}$; however, TGFB was reduced. Perhaps inclusion of other M1/M2 immunophenotype markers, such as CD80/86, tumor necrosis factor- $\alpha$, and CD163 (Thirunavukkarasu et al., 2015), as well as assessment of cytokine protein expression by BOMAC will help better discern the potential effect of $S$. cerevisiae on M1/M2 polarization in future studies.

\section{CONCLUSIONS}

The results from this study demonstrated that the exposure of $S$. cerevisiae components affected macrophage function by (1) inhibiting phagocytic activity, (2) inducing the production of ROS, and (3) altering immune-related gene expression. Bioactivity of the tested yeast components also appeared to be influenced by proprietary processing methods carried out by the industry partner. Given that S. cerevisiae components, particularly $\beta$-glucans, are commonly used as immunostimulants, the tested $S$. cerevisiae components may contribute to inducing host immunity. Therefore, application of $S$. cerevisiae components could be a novel strategy for preventing some ruminant diseases, such as Johne's disease.

\section{ACKNOWLEDGMENTS}

This research was financially supported by collaborative grants with Lallemand Inc. (Montréal, QC, Canada) and the Natural Science and Engineering Research Council of Canada (NSERC, Ottawa, ON, Canada) Engage and Engage Plus programs and the MITACS Accelerate program (Toronto, ON, Canada).

\section{REFERENCES}

Achkar, J. M., and A. Casadevall. 2013. Antibody-mediated immunity against tuberculosis: Implications for vaccine development. Cell Host Microbe 13:250-262. https://doi.org/10.1016/j.chom.2013.02 .009 .

Akira, S., T. Hirano, T. Taga, and T. Kishimoto. 1990. Biology of multifunctional cytokines: IL 6 and related molecules (IL 1 and TNF). FASEB J. 4:2860-2867.

Andrews, S. R., N. P. Sahu, A. K. Pal, S. C. Mukherjee, and S. Kumar. 2011. Yeast extract, brewer's yeast and spirulina in diets for Labeo rohita fingerlings affect haematoimmunological responses and survival following Aeromonas hydrophila challenge. Res. Vet. Sci. 91:103-109. https://doi.org/10.1016/j.rvsc.2010.08.009.

Brown, G. D., J. Herre, D. L. Williams, J. A. Willment, A. S. Marshall, and S. Gordon. 2003. Dectin-1 mediates the biological effects of beta-glucans. J. Exp. Med. 197:1119-1124. https://doi.org/10 $.1084 /$ jem.20021890.

Castro-Osses, D., C. Carrera-Naipil, C. Gallardo-Escárate, and A. Gonçalves. 2017. Functional diets modulate the acute phase protein response in Oncorhynchus mykiss subjected to chronic stress and challenged with Vibrio anguillarum. Fish Shellfish Immunol. 66:62-70. https://doi.org/10.1016/j.fsi.2017.05.001.

Dillon, S., S. Agrawal, K. Banerjee, J. Letterio, T. L. Denning, K. Oswald-Richter, D. J. Kasprowicz, K. Kellar, J. Pare, T. Van Dyke, S. Ziegler, D. Unutmaz, and B. Pulendran. 2006. Yeast zymosan, a stimulus for TLR2 and dectin-1, induces regulatory antigen-presenting cells and immunological tolerance. J. Clin. Invest. 116:916928. https://doi.org/10.1172/JCI27203.

Doreau, M., and J. Jouany. 1998. Effect of a Saccharomyces cerevisiae culture on nutrient digestion in lactating dairy cows. J. Dairy Sci. 81:3214-3221. https://doi.org/10.3168/jds.S0022-0302(98)75885 -0 .

Dower, W. J., J. F. Miller, and C. W. Ragsdale. 1988. High efficiency transformation of $E$. coli by high voltage electroporation. Nucleic Acids Res. 16:6127-6145. https://doi.org/10.1093/nar/16.13.6127.

Dubin, P. J., and J. K. Kolls. 2008. Th17 cytokines and mucosal immunity. Immunol. Rev. 226:160-171. https://doi.org/10.1111/j .1600-065X.2008.00703.x.

Dumont, A., S. P. Hehner, T. G. Hofmann, M. Ueffing, W. Dröge, and M. L. Schmitz. 1999. Hydrogen peroxide-induced apoptosis is CD95-independent, requires the release of mitochondria-derived reactive oxygen species and the activation of NF-kappaB. Oncogene 18:747-757.

Ehrt, S., and D. Schnappinger. 2009. Mycobacterial survival strategies in the phagosome: Defence against host stresses. Cell. Microbiol. 11:1170-1178. https://doi.org/10.1111/j.1462-5822.2009.01335.x.

Ellertsen, L. K., G. Hetland, E. Johnson, and B. Grinde. 2006. Effect of a medicinal extract from Agaricus blazei Murill on gene expression in a human monocyte cell line as examined by microarrays and immuno assays. Int. Immunopharmacol. 6:133-143. https:// doi.org/10.1016/j.intimp.2005.07.007.

Ganan, M., A. Carrascosa, S. de Pascual-Terese, and A. MartinezRodriguez. 2009. Inhibition by yeast-derived mannoproteins of adherence to and invasion of Caco-2 cells by Campylobacter jejuni. J. Food Prot. 72:55-59. https://doi.org/10.4315/0362-028X-72.1.55.

Ganner, A., S. Nitsch, K. Erlacher, A. Klimitsch, and G. Schatzmayr. 2010. Ex vivo effect of yeast beta-glucan on lymphocyte viabil- 
ity and plasma IL-18 in weaning piglets. Livest. Sci. 133:246-248. https://doi.org/10.1016/j.livsci.2010.06.077.

Ganner, A., and G. Schatzmayr. 2012. Capability of yeast derivatives to adhere enteropathogenic bacteria and to modulate cells of the innate immune system. Appl. Microbiol. Biotechnol. 95:289-297. https://doi.org/10.1007/s00253-012-4140-y.

Gantner, B. N., R. M. Simmons, S. J. Canavera, S. Akira, and D. M. Underhill. 2003. Collaborative induction of inflammatory responses by dectin-1 and Toll-like receptor 2. J. Exp. Med. 197:11071117. https://doi.org/10.1084/jem.20021787.

Ghoneum, M., M. Matsuura, M. Braga, and S. Gollapudi. 2008. S. cerevisiae induces apoptosis in human metastatic breast cancer cells by altering intracellular $\mathrm{Ca} 2+$ and the ratio of Bax and $\mathrm{Bcl}-2$. Int. J. Oncol. 33:533-539. https://doi.org/10.3892/ijo_00000037.

Gordon, S. 2003. Alternative activation of macrophages. Nat. Rev. Immunol. 3:23-35. https://doi.org/10.1038/nri978.

Gordon, S., and F. O. Martinez. 2010. Alternative activation of macrophages: Mechanism and functions. Immunity 32:593-604. https:// doi.org/10.1016/j.immuni.2010.05.007.

Hines, M. E., J. Kreeger, and A. Herron. 1995. Mycobacterial infections of animals: Pathology and pathogenesis. Lab. Anim. Sci. 45:334-351.

Hockenbery, D., G. Nunez, C. Milliman, R. D. Schreiber, and S. J. Korsmeyer. 1990. Bcl-2 is an inner mitochondrial membrane protein that blocks programmed cell death. Nature 348:334-336.

Hölscher, C., R. A. Atkinson, B. Arendse, N. Brown, E. Myburgh, G. Alber, and F. Brombacher. 2001. A protective and agonistic function of IL-12p40 in mycobacterial infection. J. Immunol. 167:69576966. https://doi.org/10.4049/jimmunol.167.12.6957.

Huang, Z., Q. Luo, Y. Guo, J. Chen, G. Xiong, Y. Peng, J. Ye, and J. Li. 2015. Mycobacterium tuberculosis-induced polarization of human macrophage orchestrates the formation and development of tuberculous granulomas in vitro. PLoS One 10:e0129744. https:// doi.org/10.1371/journal.pone.0129744.

Jawhara, S., K. Habib, F. Maggiotto, G. Pignede, P. Vandekerckove, E. Maes, L. Dubuquoy, T. Fontaine, Y. Guerardel, and D. Poulain. 2012. Modulation of intestinal inflammation by yeasts and cell wall extracts: Strain dependence and unexpected anti-inflammatory role of glucan fractions. PLoS One 7:e40648. https://doi.org/10 .1371/journal.pone.0040648.

Jha, A. K., A. K. Pal, N. P. Sahu, S. Kumar, and S. C. Mukherjee. 2007. Haematoimmunological responses to dietary yeast RNA, $\omega-3$ fatty acid and $\beta$-carotene in Catla catla juveniles. Fish Shellfish Immunol. 23:917-927. https://doi.org/10.1016/j.fsi.2007.01.011.

Jouany, J. P., F. Mathieu, J. Senaud, J. Bohatier, G. Bertin, and M. Mercier. 1998. The effect of Saccharomyces cerevisiae and Aspergillus oryzae on the digestion of the cell wall fraction of a mixed diet in defaunated and refaunated sheep rumen. Reprod. Nutr. Dev. 38:401-416.

Kamel, H., J. Sekine, A. El-Waziry, and M. Yacout. 2004. Effect of Saccharomyces cerevisiae on the synchronization of organic matter and nitrogen degradation kinetics and microbial nitrogen synthesis in sheep fed Berseem hay (Trifolium alexandrinum). Small Rumin. Res. 52:211-216. https://doi.org/10.1016/j.smallrumres.2003.06 .001 .

Khader, S. A., G. K. Bell, J. E. Pearl, J. J. Fountain, J. Rangel-Moreno, G. E. Cilley, F. Shen, S. M. Eaton, S. L. Gaffen, S. L. Swain, R. M. Locksley, L. Haynes, T. D. Randall, and A. M. Cooper. 2007. IL-23 and IL-17 in the establishment of protective pulmonary CD4+ T cell responses after vaccination and during Mycobacterium tuberculosis challenge. Nat. Immunol. 8:369-377. https:// doi.org/10.1038/ni1449.

Kuehnel, M. P., R. Goethe, A. Habermann, E. Mueller, M. Rohde, G. Griffiths, and P. Valentin-Weigand. 2001. Characterization of the intracellular survival of Mycobacterium avium ssp. paratuberculosis: Phagosomal $\mathrm{pH}$ and fusogenicity in J774 macrophages compared with other mycobacteria. Cell. Microbiol. 3:551-566. https://doi.org/10.1046/j.1462-5822.2001.00139.x.

Kumari, J., and P. K. Sahoo. 2006. Dietary $\beta$-1, 3-glucan potentiates innate immunity and disease resistance of Asian catfish, Clarias batrachus (L.). J. Fish Dis. 29:95-101. https://doi.org/10.1111/j 1365-2761.2006.00691.x

Kunttu, H. M., E. T. Valtonen, L. R. Suomalainen, J. Vielma, and I. E. Jokinen. 2009. The efficacy of two immunostimulants against Flavobacterium columnare infection in juvenile rainbow trout (Oncorhynchus mykiss). Fish Shellfish Immunol. 26:850-857. https:// doi.org/10.1016/j.fsi.2009.03.013.

Lamkanfi, M., R. S. Malireddi, and T. D. Kanneganti. 2009. Fungal zymosan and mannan activate the cryopyrin inflammasome. J. Biol. Chem. 284:20574-20581. https://doi.org/10.1074/jbc.M109 .023689 .

LeibundGut-Landmann, S., O. Gross, M. J. Robinson, F. Osorio, E. C. Slack, S. V. Tsoni, E. Schweighoffer, V. Tybulewicz, G. D. Brown, J. Ruland, and C. Reis e Sousa. 2007. Syk-and CARD9-dependent coupling of innate immunity to the induction of $\mathrm{T}$ helper cells that produce interleukin 17. Nat. Immunol. 8:630-638. https://doi.org/ $10.1038 /$ ni1460.

Li, Z., Q. You, F. Ossa, P. Mead, M. Quinton, and N. A. Karrow. 2016. Assessment of yeast Saccharomyces cerevisiae component binding to Mycobacterium avium subspecies paratuberculosis using bovine epithelial cells. BMC Vet. Res. 12:42. https://doi.org/10.1186/ s12917-016-0665-0.

Mead, P. 2013. Infection of monocyte-derived macrophages with a reporter Map strain: Validation of the susceptibilty SNP (-298A/G) in the bovine MIF gene. Thesis. Department of Animal Biosciences, University of Guelph, Guelph, ON, Canada.

Middelbos, I. S., M. R. Godoy, N. D. Fastinger, and G. C. Fahey. 2007. A dose-response evaluation of spray-dried yeast cell wall supplementation of diets fed to adult dogs: Effects on nutrient digestibility, immune indices, and fecal microbial populations. J. Anim. Sci. 85:3022-3032. https://doi.org/10.2527/jas.2007-0079.

Mosoni, P., F. Chaucheyras-Durand, C. Béra-Maillet, and E. Forano. 2007. Quantification by real-time PCR of cellulolytic bacteria in the rumen of sheep after supplementation of a forage diet with readily fermentable carbohydrates: Effect of a yeast additive. J. Appl. Microbiol. 103:2676-2685. https://doi.org/10.1111/j.1365 $-2672.2007 .03517 . x$.

Mukaida, N., A. Harada, and K. Matsushima. 1998. Interleukin-8 (IL8) and monocyte chemotactic and activating factor (MCAF/MCP1), chemokines essentially involved in inflammatory and immune reactions. Cytokine Growth Factor Rev. 9:9-23. https://doi.org/10 1016/S1359-6101(97)00022-1.

Newman, K. E., and M. C. Newman. 2001. Evaluation of mannanoligosaccharides on the microflora and immunoglobulin status of sows and piglet performance. J. Anim. Sci. 79:189.

Novakovic, B., E. Habibi, S. Wang, R. Arts, R. Davar, W. Megchelenbrink, B. Kim, T. Kuznetsova, M. Kox, J. Zwaag, and F. Matarese. 2016. $\beta$-Glucan reverses the epigenetic state of LPS-induced immunological tolerance. Cell 167:1354-1368. https://doi.org/10 .1016/j.cell.2016.09.034.

Olson, E. J., J. E. Standing, N. Griego-Harper, O. A. Hoffman, and A. H. Limper. 1996. Fungal beta-glucan interacts with vitronectin and stimulates tumor necrosis. Infect. Immun. 64:3548-3554.

Oltvai, Z. N., C. L. Milliman, and S. J. Korsmeyer. 1993. Bcl-2 heterodimerizes in vivo with a conserved homolog, Bax, that accelerates programed cell death. Cell 74:609-619. https://doi.org/10 .1016/0092-8674(93)90509-O.

Palm, N. W., and R. Medzhitov. 2007. Antifungal defense turns 17. Nat. Immunol. 8:549-551.

Pieters, J. 2001. Entry and survival of pathogenic mycobacteria in macrophages. Microbes Infect. 3:249-255. https://doi.org/10 .1016/S1286-4579(01)01376-4

Robinson, P. H., and J. Garrett. 1999. Effect of yeast culture (Saccharomyces cerevisiae) on adaptation of cows to postpartum diets and on lactational performance. J. Anim. Sci. 77:988-999.

Rodríguez, I., R. Chamorro, B. Novoa, and A. Figueras. 2009. $\beta$-Glucan administration enhances disease resistance and some innate immune responses in zebrafish (Danio rerio). Fish Shellfish Immunol. 27:369-373. https://doi.org/10.1016/j.fsi.2009.02.007.

Rogers, N. C., E. C. Slack, A. D. Edwards, M. A. Nolte, O. Schulz, E. Schweighoffer, D. L. Williams, S. Gordon, V. L. Tybulewicz, 
G. D. Brown, and C. Reis e Sousa. 2005. Syk-dependent cytokine induction by Dectin-1 reveals a novel pattern recognition pathway for C type lectins. Immunity 22:507-517. https://doi.org/10.1016/ j.immuni.2005.03.004.

Rubin-Bejerano, I., C. Abeijon, P. Magnelli, P. Grisafi, and G. R. Fink. 2007. Phagocytosis by human neutrophils is stimulated by a unique fungal cell wall component. Cell Host Microbe 2:55-67. https://doi.org/10.1016/j.chom.2007.06.002.

Rutledge, R. G., and C. Cote. 2003. Mathematics of quantitative kinetic PCR and the application of standard curves. Nucleic Acids Res. 31:e93. https://doi.org/10.1093/nar/gng093.

Salama, A., G. Caja, D. Garín, E. Albanell, X. Such, and R. Casals. 2002. Effects of adding a mixture of malate and yeast culture ( $S a c$ charomyces cerevisiae) on milk production of Murciano-Granadina dairy goats. Anim. Res. 51:295-303. https://doi.org/10.1051/ animres:2002025.

Schroeder, A., O. Mueller, S. Stocker, R. Salowsky, M. Leiber, M. Gassmann, S. Lightfoot, W. Menzel, M. Granzow, and T. Ragg. 2006. The RIN: An RNA integrity number for assigning integrity values to RNA measurements. BMC Mol. Biol. 7:3. https://doi .org/10.1186/1471-2199-7-3.

Seif, M., A. Philippi, F. Breinig, A. K. Kiemer, and J. Hoppstädter. 2016. Yeast (Saccharomyces cerevisiae) polarizes both M-CSF-and GM-CSF-differentiated macrophages toward an M1-like phenotype. Inflammation 39:1690-1703.

Short, D. M., D. A. Moore, and W. M. Sischo. 2016. A randomized clinical trial evaluating the effects of oligosaccharides on transfer of passive immunity in neonatal dairy calves. J. Vet. Intern. Med. 30:1381-1389. https://doi.org/10.1111/jvim.13949.

Silberberg, M., F. Chaucheyras-Durand, M. Mialon, V. Monteils, P. Mosoni, D. Morgavi, and C. Martin. 2013. Repeated acidosis challenges and live yeast supplementation shape rumen microbiota and fermentations and modulate inflammatory status in sheep. Animal 7:1910-1920. https://doi.org/10.1017/S1751731113001705.

Stabel, J. R., and T. J. Stabel. 1995. Immortalization and characterization of bovine peritoneal macrophages transfected with SV40 plasmid DNA. Vet. Immunol. Immunopathol. 45:211-220. https:// doi.org/10.1016/0165-2427(94)05348-V.

Staykov, Y., P. Spring, S. Denev, and J. Sweetman. 2007. Effect of a mannan oligosaccharide on the growth performance and immune status of rainbow trout (Oncorhynchus mykiss). Aquacult. Int. 15:153-161.

Thirunavukkarasu, S., K. de Silva, D. J. Begg, R. J. Whittington, and K. M. Plain. 2015. Macrophage polarization in cattle experimentally exposed to Mycobacterium avium ssp. paratuberculosis. Pathog. Dis. 73:ftv085. https://doi.org/10.1093/femspd/ftv085.

Torrecillas, S., A. Makol, M. J. Caballero, D. Montero, L. Robaina, F. Real, J. Sweetman, L. Tort, and M. S. Izquierdo. 2007. Immune stimulation and improved infection resistance in European sea bass (Dicentrarchus labrax) fed mannan oligosaccharides. Fish Shellfish Immunol. 23:969-981. https://doi.org/10.1016/j.fsi.2007 .03 .007 .

van de Veerdonk, F. L., L. A. Joosten, I. Devesa, H. M. Mora-Montes, T. D. Kanneganti, C. A. Dinarello, J. W. van der Meer, N. A. Gow, B. J. Kullberg, and M. G. Netea. 2009. Bypassing pathogeninduced inflammasome activation for the regulation of interleukin$1 \beta$ production by the fungal pathogen Candida albicans. J. Infect. Dis. 199:1087-1096. https://doi.org/10.1086/597274.
Van Seventer, G. A., Y. Shimizu, K. J. Horgan, G. E. Luce, D. Webb and S. Shaw. 1991. Remote T cell co-stimulation via LFA/ICAM1 and CD2/LFA-3: Demonstration with immobilized ligand/mAb and implication in monocyte-mediated co-stimulation. Eur. J. Immunol. 21:1711-1718. https://doi.org/10.1002/eji.1830210719.

Veterinary Laboratories Agency (VLA). 2008. Johne's disease continues to be the most common cause of bovine enteric disease. Vet. Rec. 163:171-174.

Vetvicka, V., B. P. Thornton, and G. D. Ross. 1996. Soluble betaglucan polysaccharide binding to the lectin site of neutrophil or natural killer cell complement receptor type 3 (CD11b/CD18) generates a primed state of the receptor capable of mediating cytotoxicity of iC3b-opsonized target cells. J. Clin. Invest. 98:50-61. https://doi.org/10.1172/JCI118777.

Volman, J. J., J. D. Ramakers, and J. Plat. 2008. Dietary modulation of immune function by $\beta$ - glucans. Physiol. Behav. 94:276-284. https://doi.org/10.1016/j.physbeh.2007.11.045.

Wakshull, E., D. Brunke-Reese, J. Lindermuth, L. Fisette, R. S. Nathans, J. J. Crowley, J. C. Tuffs, J. Zimmerman, W. Mackin, and D. S. Adams. 1999. PGG-glucan, a soluble $\beta$-(1, 3)-glucan, enhances the oxidative burst response, microbicidal activity, and activates an NF- $\kappa$ B-like factor in human PMN: Evidence for a glycosphingolipid $\beta$-(1, 3)-glucan receptor. Immunopharmacology 41:89-107. https: //doi.org/10.1016/S0162-3109(98)00059-9.

White, L. A., M. C. Newman, G. L. Cromwell, and M. D. Lindemann. 2002. Brewers dried yeast as a source of mannan oligosaccharides for weanling pigs. J. Anim. Sci. 80:2619-2628. https://doi.org/10 $.2527 / 2002.80102619 x$

Whitlock, R. H., and C. Buergelt. 1996. Preclinical and clinical manifestations of paratuberculosis (including pathology). Vet. Clin. North Am. Food Anim. Pract. 12:345-356. https://doi.org/10 .1016/S0749-0720(15)30410-2.

Williams, D. L. 1997. Overview of $(1 \rightarrow 3)$-beta-D-glucan immunobiology. Mediators Inflamm. 6:247-250.

Williams, P. E., C. Tait, G. Innes, and C. Newbold. 1991. Effects of the inclusion of yeast culture (Saccharomyces cerevisiae plus growth medium) in the diet of dairy cows on milk yield and forage degradation and fermentation patterns in the rumen of steers. J. Anim. Sci. 69:3016-3026. https://doi.org/10.2527/1991.6973016x.

Willment, J. A., S. Gordon, and G. D. Brown. 2001. Characterization of the human $\beta$-glucan receptor and its alternatively spliced isoforms. J. Biol. Chem. 276:43818-43823. https://doi.org/10.1074/ jbc.M107715200.

Wohlt, J. E., T. Corcione, and P. Zajac. 1998. Effect of yeast on feed intake and performance of cows fed diets based on corn silage during early lactation. J. Dairy Sci. 81:1345-1352. https://doi.org/10 .3168/jds.S0022-0302(98)75697-8.

Yang, E., and S. J. Korsmeyer. 1996. Molecular thanatopsis: A discourse on the BCL2 family and cell death. Blood 88:386-401.

Yu, H. B., and B. B. Finlay. 2008. The caspase-1 inflammasome: A pilot of innate immune responses. Cell Host Microbe 4:198-208. https://doi.org/10.1016/j.chom.2008.08.007.

Zhou, T. X., J. H. Jung, Z. F. Zhang, and I. H. Kim. 2013. Effect of dietary $\beta$-glucan on growth performance, fecal microbial shedding and immunological responses after lipopolysaccharide challenge in weaned pigs. Anim. Feed Sci. Technol. 179:85-92. https://doi.org/ 10.1016/j.anifeedsci.2012.10.008. 